\title{
Designing Sustainable Open Source Systems: The Cuban National Health Care Network and Portal (INFOMED)
}

\author{
Ann Séror \\ eResearch Collaboratory, Quebec City, Canada \\ annseror@eresearchcollaboratory.com
}

\begin{abstract}
Integrating research, education and evidence-based medical practice requires complex network linkages among these critical activities. This study examines the Cuban National Health Care Network and Portal (INFOMED) in the context of the regional Virtual Health Library of the Latin American and Caribbean Health Sciences System (BIREME) led by Brazil. INFOMED is a virtual infrastructure for integration of scientific research with education and expert intervention in evidence-based medicine. Virtual infrastructures refer to an environment characterized by overlapping distribution networks accessible through Internet portals and websites designed to facilitate integrated use of available resources. The objective of this paper is to examine system design at the regional and national levels of analysis using theoretical perspectives from complexity theory, institutional economics and knowledge ecology. In conclusion model transferability to other national health care systems is considered.
\end{abstract}

Keywords: Cuba, national health care systems, INFOMED, qualitative research methods, virtual infrastructures, open source software.

\section{Introduction}

Recent literature in development, sustainability and health care has recognized the importance of comparative research on large systems for understanding of complexity and performance at the national and global levels of analysis (Reimers et al., 2010). Despite recognition of the importance of systems science in medical informatics(Coiera, 2003), only fragmented progress has been made in theory development and research methods to address issues of critical importance in large scale health care system reform. The objective of this research is to contribute to an interdisciplinary perspective on theory and methods for this emerging scientific domain.

The diversity of such systems means that technology varies, in particular as a function of technological choices based on local and regional ideologies and traditions. The boundaries of the ecological field under study pose both conceptual and methodological dilemmas. (Thrift, 2006) The health care system is defined here as a complex set of interconnected individuals, institutions, organizations, and projects offering products and services in health care markets (Alliance for Health Policy and Systems Research, 2004). The functions of the health care system include 
all categories of service delivery, resource generation and allocation, and governance. Service delivery encompasses information, research, and educational services as well as public health and delivery of patient care, both preventative and curative. Performance of complex health care systems depends on patterns of interdependence of these diverse system functions through extended interorganizational information systems and virtual infrastructures. Virtual infrastructures refer to an environment characterized by overlapping distribution networks, systems brokerage functions, and the adoption of a software perspective emphasizing the devices and channels through which information is processed and distributed (Séror, 2006a).

Integration of health information systems at the country and regional levels of analysis is particularly evident in the Latin American and Caribbean Health Sciences System (BIREME) led by Brazil, national systems share common ideologies (Committee for Economic Development (CED), 2006) associated with universal health care, public education in medicine and the health sciences, open access publishing of health information and research, and infrastructure creation through open source software development. ${ }^{1}$ The principle of open access ${ }^{2}$ is the responsibility to extend the unrestricted availability of scientific information and research publications to all who may be interested or have need of it (Albert, 2006;Cockerill, 2006;Willinsky, 2006). Similarly, open source software development is founded on the principles of freely shared source code with a license that permits redistribution as well as the creation of derived works (Benkler, 2001;Edwards, 2001). Some experience suggests that the open source model for software development may be extended to research in the health sciences, pointing to the ideological coherence between infrastructure development and productive activities conducted within such infrastructure(Maurer et al., 2004;Mueller, 2008;Scacchi \& et al., 2010).

A useful perspective on this system driven by the open source model is complexity theory. Characteristics of complex systems include emergent properties and qualitative rather than incremental change. (Byrne, 2009; Kannampallil et al., 2011). INFOMED within the larger network of BIREME can be viewed as a complex adaptive system of nested entities(Dagnino, 2004). Open source systems possess the capability to grow and self-organize through sharing of tools and resources. The selforganizing system adapts to its environment with the capacity to replicate and renew itself from within. These systems may be considered closed by virtue of the rules of interaction, while at the same time they are open as they extend - for example - from one national entity to another. Coevolution of INFOMED and other national health information systems within BIREME also affects the distribution of roles at regional and nested national levels of analysis. As nested entities coevolve, emergent features transform the larger system. (Morrison, 2008)

\footnotetext{
${ }^{1}$ The ideology shared by these related communities of practice may also profoundly affect the broader functions of the knowledge ecology, including the conduct of research and delivery of care. (Anonymous, 2004;Benkler, 2002;Maurer et al., 2004).

${ }^{2}$ See the Public Library of Science definition of open access at http: / /www.plos.org/oa/definition.html (accessed 28 April 2008).
} 
Open access publication remodels information flows across virtual spaces with no exchange of physical materials or financial transactions in a process of shared content development and ever reduced restrictions on access to health information.(Packer, 2000) While online publication extends global access to both international and local scientific journals, the linkage between these resources may be configured to contextualize user knowledge and practice. (Ofori-Adjei et al., 2006) The shared space linked through virtual infrastructures of the health information system is defined here as a knowledge ecology - including institutional and network portals, electronic journals and other resources, online courses, collaborative spaces, human resources, and search engines arranged according to language, knowledge domain, or geographical location.

Trist suggested as early as 1977 the importance of "clustering" in social ecologies and the need for inquiry into the cognitive mapping of large scale socio-ecological systems characterized by network structures expressing negotiated rather than bureaucratic order. (Trist, 1977) He identified conceptual and methodological difficulties posed by this new area of inquiry. First, the ecological domain is difficult to identify - requiring a "figure-ground reversal" to render its features observable or measurable. Second, the structure of middle-level fields - bridging the divide between local and global(Barrett et al., 2005) - is particularly elusive, as singular institutions are generally more visible in networks than - for example - chambers of commerce or regulatory councils. Virtual infrastructures made visible on the Internet reflect the resources of the knowledge ecology. These institutional infrastructures may control access to associated resources through regulatory or certification processes, or they may be created and controlled by their constituencies through membership and democratic governance. Where no referent structures order the system, market dynamics and ideologies determine the configuration of the ecological domain(Séror, 2011).

Virtual infrastructures of INFOMED - accessible on the Internet - offer visible evidence of ecological domains for mapping and analysis of their configurations at micro-, meso- and meta-levels of structure. The research objectives here are to describe INFOMED in the context of BIREME as a complex knowledge ecology using qualitative case analysis - and to make some recommendations regarding national strategies for model transferability.

This case analysis contributes to a broad research program designed to develop a framework for comparative analysis of national health care system infrastructures using qualitative case research methods. (Séror, 2012, 2011, 2002, 2006a, 2006b). The next section of the paper describes the methodology for study of the Cuban National Health Care Network and Portal (INFOMED).

\section{Research Methodology}

The research methodology used for this study is embedded qualitative case analysis(Hannan, 2005;Yin, 1999;Yin, 2009). The regional and national infrastructures selected for study - the Latin American and Caribbean Health Sciences 
System (BIREME) as a context for the Cuban National Health Care Network and Portal (INFOMED) - form a complex interorganizational information system (Byrne, 2009;Reimers et al., 2010) (Dagnino, 2004). Such large, complex systems pose significant challenges to design of research methods for a number of reasons. First, the degree of interrelatedness and the evolutionary nature of system change make it very difficult to identify a nomological model (Kannampallil et al., 2011). Second, the process definition of causality associated with the scientific method (Morrison, 2012) cannot be applied in development of theoretical frameworks, nor can it be the objective of research designs focused on complexity. Rather, the lens of complexity theory suggests an interconnected system with reciprocal relationships for mutual constitution of the observed characteristics of the system (Reimers et al., 2010).

Specifically this is an embedded case according to the typology suggested by Yin (2009) where the regional BIREME forms the context in which INFOMED has grown and developed at the Cuban country level of analysis. This choice of case is revelatory of the reciprocal roles of regional and country level leadership in health information system development. The Cuban case is unique, in some ways offering a natural experiment in the values of social medicine. While this study may not yield generalizable conclusions, it sheds light on the critical coevolution of regional and national knowledge ecologies and the ideological role of the social medicine model shared among countries of the Latin American region (Collier \& Mahoney, 1996). Historical description of the institutional context shows how virtual infrastructures have emerged over time and how this temporal evolution has affected the forms and functions expressed in the system ecology (Bennett \& Elman, 2006).

Data include published accounts of system development and the websites of the constituent organizations, networks and services to describe the configuration of virtual infrastructures(Vidal Ledo et al., 2007). The mapping methodology reveals complex infrastructural patterns of health care information system management and control(Rodriguez Pina \& Guerra Avila, 2008). Qualitative interpretation facilitates identification of complex and sometimes paradoxical effects of information and communication technologies on knowledge ecologies (Robey \& Boudreau, 1999). Emapping software ${ }^{3}$ is used to visualize maps of the linkages among resources identified in the knowledge ecology of the Cuban National Health Care Network and Portal (INFOMED) in the context of the regional Virtual Health Library of the Latin American and Caribbean Health Sciences System (Egbu \& et. al, 2006;Ruffini, 2008). The maps generated using this methodology show how global, regional and national resources are shared and integrated in the virtual infrastructure (Ebener et al., 2006; Lavis et al., 2006). Figure 1 below shows a partial view of a map of INFOMED. Nodes in this map identify virtual organizations and resources. Edges represent Internet linkages among these virtual entities. The resulting configuration reveals the relational logic of the system as well as patterns of connectedness and selforganization both within INFOMED and among emergent entities of BIREME. Figure 1 below shows a partial view of a map of INFOMED. This database is available online for review.

\footnotetext{
${ }^{3}$ See The Brain - Visual Information Management at http: / /www . thebrain. com/
} 


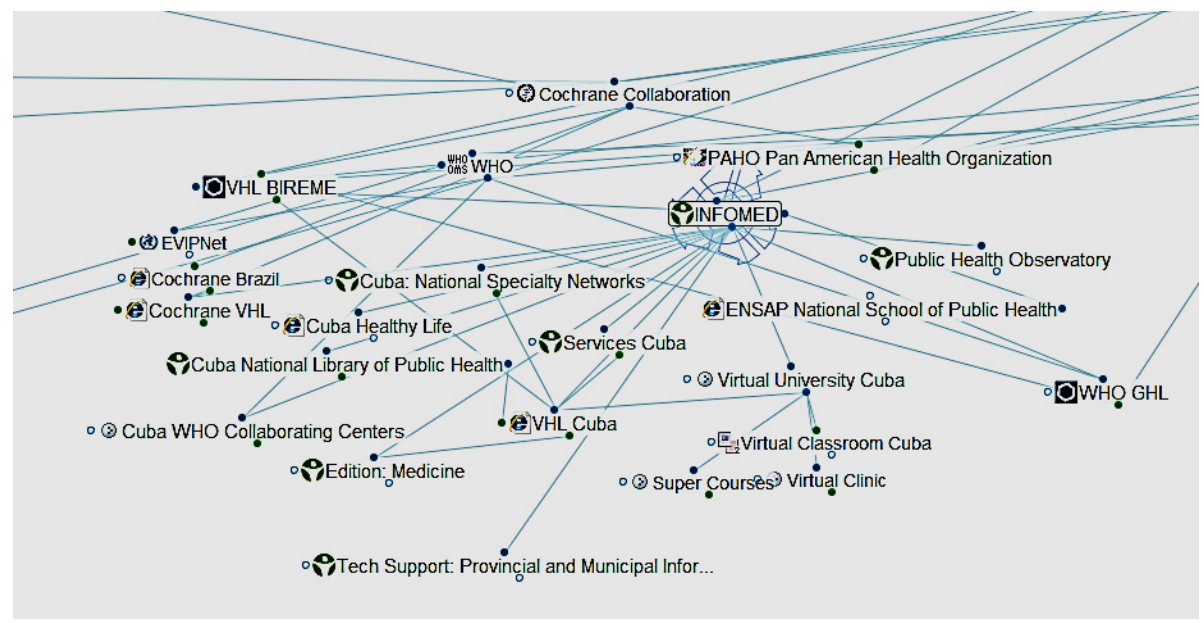

Fig. 1. The virtual infrastructure of INFOMED

\section{Case Analysis}

According to Article 4 of the Cuban Public Health Law No. 43, the ideological principles underpinning Cuban health care services include (Asamblea Nacional del Poder Popular de la República de Cuba, 1983): adequate health care defined as a human right, free and universal access to health care services offered by the state, emphasis on preventive care, and active participation of the population in public health promotion. The performance of this national system is reflected in statistics for population life expectancy of 78 years (2009) and infant mortality of 5 per thousand live births - indicating standards similar to those observed in the developed countries. Expenditure per capita of $\$ 495$ contrasts sharply with the US expenditure of $\$ 7,164$ in 2008, particularly in light of poor US performance among other OECD countries(Davis et al., 2010). Also significant is the concentration of 64 physicians per 10,000 population (2000-2010) - the highest in the world (World Health Organization, 2011).

Since the Cuban revolution in 1959, the country's leadership have pursued strategies to integrate national research and innovation policies through development of traditional institutions and, since 1990, information and telecommunication infrastructures(Amaro, 2000;Capote, 1996;Séror \& Fach Arteaga, 2000). In 1963, municipal polyclinics were first created to form the basic units of the Cuban health care system and to manage all health care activities within their jurisdictions, including workplaces, schools, and childcare centers. These activities were the first programs of the current community-based health care model(Campion \& Morrissey, 2013;Keck \& Reed, 2012;Séror, 2006a). In 1965 the National Center for Scientific Research (Centro Nacional de Investigaciones Cientificas, CNIC) and the National Information Center for the Medical Sciences (Centro Nacional de Información de Ciencias Médicas de la República de Cuba-CNICM) were founded to serve the institutional needs of science and research in health care. 
Coordinated by CNICM, The Cuban National Health Care Network and Portal (INFOMED) was founded in 1992 with support from the United Nations Development Program, the World Health Organization, the Pan-American Health Organization, and UNICEF. INFOMED serves the health information requirements of Cuban health care professionals. (Figure 2 shows a screenshot of the INFOMED Portal.) As the network was extended throughout the 14 Cuban provinces, it provided health care workers' access to information - connecting provincial information centers, research institutes, hospitals and universities(Séror, 2006a). While the Cuban Ministry of Public Health is generally responsible for hierarchical governance of the Cuban National Health Care System, the mission of INFOMED is to integrate research, education and evidence-based practice through telecommunications and information technologies(Rodríguez Pérez \& Urra González, 1996;Urra González, 1995).

Largely developed with open source software, the virtual infrastructures associated with INFOMED support processes of information and communication throughout the system. The Cuban open source software development community collaborates closely with scientific and administrative communities of practice through shared ideological values expressed in open access to health information and universal health care services (Schweik \& Semenov, 2003).

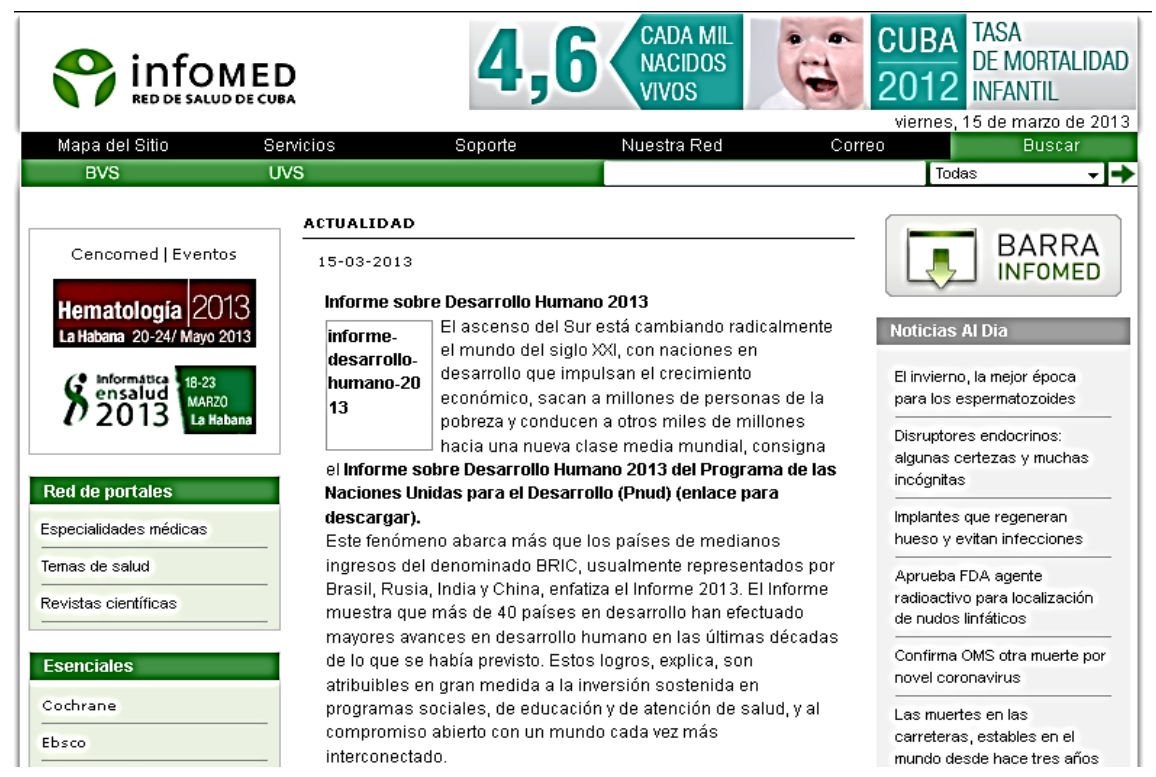

Fig. 2. The INFOMED Portal at http://www.sld.cu/ (accessed 15-3-2013)

In particular, BIREME forms the context for development of national health information systems serving Latin America. It was founded in 1967 with the collaboration of the Brazilian Ministry of Education, Ministry of Health, Secretary of Health of the State of São Paulo, and the Federal University of São Paulo as a specialized center of the WHO regional office for the Americas, the Pan American Health Organization (PAHO). Recognizing that an important condition for the 
development of health is universal, equitable and cost-effective access to scientific and technical information in medicine and the health sciences, BIREME aims to promote the regional capacity for collaboration to through open access to data and research on medicine and the health sciences. Throughout its history, BIREME's technical operation has been motivated by the principles of decentralized networking, local capacity building, cooperative product development, and elaboration of common methodologies(BIREME, 1998;BIREME, 2008;Bireme, 2011).

Such cooperative projects linked to the INFOMED Portal include the Cuban VHL $^{4}$ and the Virtual University ${ }^{5}$ offering online training in medicine and the health sciences. Since 1994, the Cuban National Library of Medicine (CNLM) ${ }^{6}$ has collaborated with BIREME to develop the Collective Catalogue of Periodical Publications on the Health Sciences (SeCiMed). ${ }^{7}$ In 1998 when the regional VHL was created, the CNLM was converted into a network coordinating center- including 815 libraries and information centers - charged with compiling the Cuban medical bibliography for the regional LiLaCS project led by BIREME. ${ }^{8}$ The CNLM played a critical role in the transition to new media for information dissemination to both real and virtual library users.

The Cuban VHL has grown to include more than 50 online Spanish-language journals in medicine and public health. These publications have been formally certified according to standards ${ }^{9}$ set by the Cuban Ministry of Science, Technology and the Environment(CITMA, 1994). In 2001, Cuba joined the SciELO Network, and adopted the SciELO methodology(Packer, 2007). ${ }^{10}$ The SciELO network serves to promote selected Cuban journals in the international scientific information flow through network access, search tools, and article indexing(Cañedo Andalia et al., 2010). The Cuban VHL links information and research from the Latin American region as well as international scientific research and accounts of medical experiences in developing countries. More than 25 countries of the Latin American region have appropriated models, methods and open source tools to create national virtual libraries connected to the regional network managed by BIREME. ${ }^{11}$

Although English is the international language of science, other languages are essential to the culture and context of health care systems. The Virtual Health Library (VHL) linking BIREME and INFOMED embody an institutional commitment to Spanish and Portuguese languages and context while maintaining linkages to English and French language resources. Shared Spanish and Portugese languages as well as the

\footnotetext{
${ }^{4}$ Cuban Virtual Health Library at

http: / / www. bvscuba.sld.cu/html/es/home.html

${ }^{5}$ Virtual University at http: //www. uvs.sld.cu/

${ }^{6}$ CNLM website at http: / /www.sld.cu/sitios/bmn/

${ }^{7}$ SeCiMed website at http://bmn.sld.cu/secimed/msrc/secimed_home.php

${ }^{8}$ See an account of the history of the CNLM at http: / / www.sld.cu/sitios/bmn/temas.php?idv=2381

9 These journal quality standards include national registration and accreditation by an appropriately formed national commission. Article evaluation must be completed by qualified referees and certified journals must include content of at least $60 \%$ original scientific research.

${ }^{10}$ SciELO Cuba website - http: / / scielo.sld.cu/scielo.php

${ }^{11}$ http: //regional .bvsalud.org/php/bvsnet . php?lang=en\&list=countries
} 
values of open source systems contribute to growth and self-organization of BIREME and INFOMED. This commitment is especially critical to the interests of Cuban scientists and practitioners as they adopt medical innovation from scientific communities of the developed world and identify topics of common concern for international collaboration(Meneghini et al., 2006;Meneghini \& Packer, 2007).

The Cuban Virtual University for the Health Sciences (UVS) was founded by the Ministry of Public Health in 1998 to improve continuing post graduate medical training for more than one hundred thousand Cuban health care professionals and to offer an international center for postgraduate education in medicine and related disciplines(Lalas Perea et al., 2000;Ramírez Machado et al., 2002). This institution links the Cuban health care information and publication infrastructure with Cuban institutions for higher education as well as supercourses with Cuban ${ }^{12}$ and international content such as Epidemiology, the Internet, and Global Health ${ }^{13}$ hosted by the University of Pittsburgh. In 2004, a learning environment, the Virtual Classroom was created and in 2005, migrated to open-source Moodle, a scalable course management system also used in the Virtual Campus for Public Health.

In 2006 the Cuban Virtual University adopted Plone, an open-source content management system $^{14}$ to extend university community participation through open courses, event management, and a repository for learning resources. (Díaz Martínez et al., 2010) The collaborative environment for website development fosters service decentralization, user participation, and integration of technology, management and pedagogy. (Jardines Méndez, 2006a;Jardines Méndez, 2006b;Zacca González G. et al., 2008) Members of Cuban university communities including professors and other users collaborate to create and publish content made available through the network. Essential components of the Virtual University are the Virtual Classroom, the Interactive Clinic, the Repository for documents of interest, and the network through which courses are offered. The Virtual Classroom supports medical training and education $^{15}$ while the Interactive Clinic provides a forum for discussion on diagnostics and case studies. ${ }^{16}$ The Repository is an electronic archive of documents such as courses, conference presentations and scientific articles made available to the university community. Courses may be offered through the network for medical education credit using the Moodle interface, or content may be made available for autonomous learning according to the MIT open courseware model. ${ }^{17}$

Associated with the Virtual University is the Cuban Virtual Campus for Public Health $(\mathrm{VCPH})^{18}$ linked to the Latin American infrastructures created by PAHO. ${ }^{19}$ This virtual infrastructure now links the $\mathrm{VCPH}$ in 11 countries of the region. This

\footnotetext{
${ }^{12}$ Cuban Super Course site at http: / / supercurso.sld.cu/

${ }^{13}$ Supercourse-Epidemiology, the Internet, and Global Health, University of Pittsburgh: http: / /www.pitt.edu/ super1/

${ }^{14}$ www.plone.org

${ }^{15}$ Virtual Classroom - http: //aulauvs.sld.cu/

${ }^{16}$ Interactive Clinic - http: / / www. uvs.sld.cu/clinica

${ }^{17}$ http: //mit. ocw. universia.net/ and the associated Universaria at http://www. universia.net/\#noticias

${ }^{18}$ Cuban Virtual Campus at http: / / cuba . campusvirtualsp.org/

${ }^{19}$ http: / / regional .bvsalud. org/php/bvsnet . php? lang=en\&list=countries
} 
interactive community replicates the model of the regional VCPH in national health information systems, and connects Cuban institutions in health sciences research and education including the School of Public Health, ${ }^{20}$ the Pedro Kourí Tropical Medicine Institute, $^{21}$ the Institute for Hygiene, Epidemiology and Microbiology, ${ }^{22}$ the Occupational Health Institute, ${ }^{23}$ and the Center for Development of Pharmacoepidemiology. ${ }^{24}$ Like the Cuban Virtual University, the VCPH promotes communities of practice through a collaborative environment for creating content, sharing and developing resources throughout the national network. These shared tools and infrastructures create synergies among local, national and regional health information systems.

INFOMED also offers networked infrastructures serving evidence-based practice of medical specialties including participation in clinical trials(Reveiz et al., 2011). The methodology for creation of the Paediatric Surgery National Network (Red Nacional de Cirugía Pediátrica -RENACIP) - the first such specialized network in.

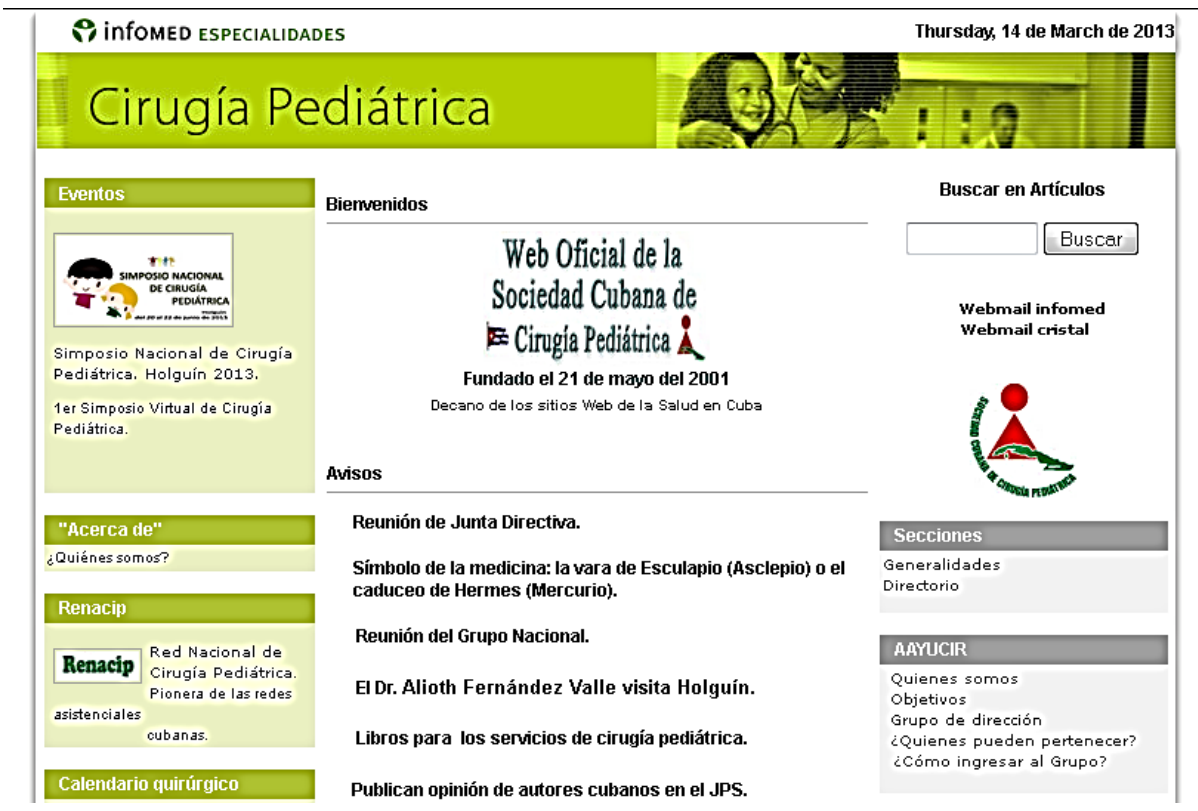

Fig. 3. The RENACIP Portal at http://www.sld.cu/sitios/renacip/(accessed 15-3-2013)

Cuba - demonstrates how human resources and technology are integrated in the Cuban model(Séror, 2006a). The institution to lead the network, the Paediatric Teaching Hospital "Octavio de la Concepción de la Pedraja" of Holguín, was

\footnotetext{
${ }^{20}$ http: / / www. ensap.sld.cu/

${ }^{21}$ http://www.ipk.sld.cu/indicel.htm

22 http: //www.inhem.sld.cu/

${ }^{23}$ http://www.sld.cu/sitios/insat/index.php

${ }^{24}$ http: //www.cdf.sld.cu/
} 
designated by the Cuban Ministry of Public Health in 2001 (Trinchet Soler \& Pedrianes Vigo, 2004;Trinchet Soler, 2006). During the initial phase, the local hospital network was developed to integrate the practice of other specialties essentialto paediatric surgery, including radiology, endocrinology, and neurophysiology. The national network began with identification of experts in three regions of the country for consultation in complex cases. A discussion list was used as a tool to scale up the specialized health information system from the hospital to the national level for improved decision making, allocation of resources, and more efficient care. Figure 3 shows a screenshot of the RENACIP Portal.

Consistent with the principles of evidence-based medicine, the specialists of the national RENACIP network have identified best practice protocols through professional meetings and virtual consultation. These protocols are available to health care practitioners on the Internet ${ }^{25}$ (Díaz Mastellari, 1999-2006). Other features of RENACIP include a portal, ${ }^{26}$ a virtual library collection of scientific publications, and software tools for patient management. Software development and website design are closely adapted to the network activities of research and evidence based practice as scientists and physicians participate directly in website design and related communities of practice. ${ }^{27}$ Within RENACIP, groups associated with subspecialties in paediatric surgery are also being formed - including orthopedics, oncology, and urology. This evolution since the creation of RENACIP illustrates nesting of self-organizing entities.

The model first used for development of RENACIP has been extended to more than 45 medical specialties, linking provincial institutions and resources to the national health information system ${ }^{28}$ and providing centralized web-based services through the INFOMED portal. The extension of networks for medical specialties illustrates the principles of self-organization as the methods and open source tools originally developed for the RENACIP network are appropriated for creation of national networks serving other medical specialties.

The participation of human resources and communities of practice at the provincial and national levels is critical as health care workers become active information and knowledge producers Since 2002 a process of consultation (Earl et al., 2001;Persaud \& Nestman, 2006) engages institutions of the health care system including the Ministries of Public Health and Higher Education to identify the strategic objectives of INFOMED (Infomed, 2011;Ministerio de Salud Pública, 2010;PrietoDíaz et al., 2011):

- To develop the Virtual Library as an interactive work space linking institutional resources of national, provincial and municipal libraries to respond to Cuban as well as international health care priorities.

${ }^{25}$ See the RENACIP best practice protocols at http://www.sld.cu/galerias/doc/sitios/renacip/gbpc_aprobadas.d oc and http://www.sld.cu/sitios/renacip/temas.php?idv=4415

${ }^{26}$ See the RENACIP Portal at http: / /www.sld.cu/sitios/renacip/

${ }^{27}$ See ProyectoWeb, the Cuban web design community at http: / / www. proyectoweb. info/

${ }^{28}$ See the list of specialized networks at http://www.sld.cu/verpost.php?blog=http://articulos.sld.cu/edi torhome /\&post_id=5257\&tipo=1\&opc_mostrar $=2 \_\& n=z$ 
- To build technical, organizational and human resource infrastructures for sustainable institutional growth in information services.

- To promote publication of Cuban research in the health sciences and related disciplines for access by national and international scientific communities.

- To improve the technological and methodological infrastructures of the Virtual University serving a health education network.

- To create a system-wide health information intranet linking the Center for Health Information Sciences and networks of provincial institutions.

- To continue to develop the Cuban research base in the field of health information sciences and medical informatics.

- To foster integration of INFOMED with other national and international health information networks and infrastructures.

- To develop methodologies and protocols for continuous and systematic evaluation and control of INFOMED's performance.(Cañedo Andalia \& López Espinosa, 2009;Cañedo Andalia, 2009)

These objectives guide concurrent processes of local system empowerment, centralized coordination and control through INFOMED, and growing integration of Cuban and regional infrastructures - the Virtual Library led by BIREME and the Virtual Campus for Public Health founded by PAHO. The emergence of these regional institutions has transformed the knowledge ecology of BIREME. Of particular importance for integration of regional and national health information systems is the coherence between system design and the social medicine values underpinning these infrastructures - including universal health care, open access to health information, and focus on collective social and environmental dimensions of health.

INFOMED effectively mediates a dual market system designed to protect these internal social values while creating links to external global markets beyond national boundaries. Strong research and innovation within the Cuban system contributes to productive evaluation, adaptation and integration of regional infrastructures as well as use of research results and evidence from external sources in Cuban health care.

\section{Discussion and Conclusions}

The embedded case analysis through the lens of complexity theory offers an understanding of the Cuban national strategy for development of virtual infrastructures supporting health care services and research. The historical evolution of both the regional and national virtual infrastructures suggests that the founding commitment to the Latin American ideological tradition of social medicine - as expressed in Cuban legislation for public health - has shaped development of both INFOMED and BIREME, and made possible the effective integration of health information networks at the regional and national levels of analysis. These systems reflect the critical importance of traditional local institutions in coordinating the transition from paper media to the open access publication model embodied in the Cuban Virtual Health Library and the regional VHL. The Cuban Virtual University has also made possible effective linkage with the VCPH. The co-evolution of 
regional and national health information systems including virtual libraries and universities demonstrates how open source software systems, standards and methodologies for development of infrastructure offered at the regional level are appropriated at the national level to support local scientific capacity embodied in communities of practice for education and knowledge creation. This process effectively illustrates the dynamics of nested complex systems adapting to their environment and self-organizing in INFOMED and other national health information systems.

These complex dynamics are particularly evident in the way methodologies including SciELO - associated with the regional BIREME VHL - are appropriated for development of the Cuban VHL. The same process is identified in replication of VCPH collaborative spaces for virtual classrooms, document repositories, and wikis within the Cuban VCPH and Virtual University. This process of appropriation is facilitated by the shared ideology of open source software development and open access to health information and research. The collaborative spaces of the Virtual University, the Virtual Campus for Public Health and the Virtual Library integrate the open flow of health information with the creative dynamics of scientific and professional communities of practice. Situated learning in this context also challenges the linear model of research, development, learning and practice, where researchers and practitioners are mutually engaged(Edwards, 2001; McDonald \& Viehbeck, 2007).

While in other developing countries, virtual infrastructures for health care services are often designed to compensate for the lack of trained health care professionals; in the Cuban context, a high concentration of qualified multi-skilled human resources is a distinctive feature of the system. Throughout INFOMED, webmasters are often practicing physicians and scientists contributing their efforts according to a model similar to that for collaboration in open source software development. The Cuban experience suggests that this model may be useful for medical research, development and education supported by the culture of open source software communities(Benkler, 2003;Committee for Economic Development (CED), 2006;Lanzara \& Morner, 2003; Maurer et al., 2004; Schweik \& Semenov, 2003).

The Cuban strategy for development of INFOMED and associated virtual infrastructures for health information, education, research and service delivery is thus founded on coherency among a strong national socialist ideology, shared culture including language and literacy, universal and free access to health care, open access to health information and research in the health sciences, as well as open source software, tools and methodologies to build infrastructures, products and services. Consistent with the view of a complex system as both an open and closed, INFOMED offers a strong centralized planning process and tools for development of networks and websites-essential for network membership and system growth. The development of the methodology for creation of RENACIP illustrates a successful strategy subsequently applied to extend the model to a growing number of medical specialties with networks on a national scale. This example also reveals application of the RENACIP model to develop subspecialties within paediatric surgery.

Strategies identified in this study for development of virtual infrastructures and a national health information system are unique to the Cuban context and their transferablility to other systems requires careful evaluation of contextual factors in 
other developing countries as well as the industrialized world. The social medicine model promotes centralized planning and public investment in every aspect of the health care system, including health information technology and virtual infrastructures. The single payer system effectively reduces the administrative burden in the health care sector. Market dynamics and transactions pose obstacles to the free flow of information and the ease of collaboration among medical scientists, technologists and practitioners - as seen in a case comparison of the U.K. NHS and the U.S. Kaiser Permanente (Séror, 2002). Social, cultural and ideological diversity challenge the success of these strategies - as observed in the Indian national case. (Séror, 2011).

Future research efforts should focus on innovative methodologies as well as theory development for the study of large scale health information systems. Particular attention needs to focus on coevolution and integration of ideological models for social medicine and capitalist market models of national health care systems. Embedded case studies will be also useful for understanding system dynamics between national and regional levels as well as the respective roles of virtual infrastructures and communities of practice in creation of health information and knowledge. Programs of comparative case studies across regional and national systems are essential to understanding of ideology, culture and technology as determinants of sustainable global system configuration.

\section{References}

Albert, K.M.: Open Access: Implications for Scholarly Publishing and Medical Libraries. Journal of the Medical Library Association 94, 253-262 (2006)

Alliance for Health Policy and Systems Research: Strengthening Health Systems: The Role and Promise of Policy and Systems Research (2004)

Amaro, N.: Models of Development and Globalization in Cuba. ASCE, Cuba in Transition 10, 277-287 (2000)

Anonymous: An Open-Source Shot in the Arm? The Economist, (2004)

AsambleaNacionaldelPoderPopular de la República de Cuba: Ley $N^{o}$ 41. Ley De La SaludPública (1983)

Barrett, M., Fryatt, B., Walsham, G., et al.: Building Bridges between Local and Global Knowledge: New Ways of Working at the World Health Organisation. Knowledge Management for Development Journal 1, 31-46 (2005)

Benkler, Y.: Freedom in the Commons, Towards a Political Economy of Information. Duke Law Journal 52 (2003)

Benkler, Y.: Coase'sPenguin,Or Linux and the Nature of the Firm. Yale Law Journal 112, 369 (2002)

Benkler, Y.: The Battle Over the Institutional Ecosystem in the Digital Environment. Communications of the ACM 44, 84-90 (2001)

Bennett, A., Elman, C.: Complex Causal Relations and Case Study Methods: The Example of Path Dependence. Political Analysis 14, 250-267 (2006)

Bireme: VHL Guide (2011), http: / /guiabvs2011. Bvsalud.org/en/presentation/

BIREME: Access to Information Sources in Virtual Health Library-VHL (2008) 
BIREME: Towards the Virtual Health Library (1998)

Byrne, D.: Working within a Complexity Frame of Reference- the Potential of 'Integrated Methods' for Understanding Transformation in Complex Social Systems (2009)

Campion, E.W., Morrissey, S.: A Different Model - Medical Care in Cuba. N. Engl. J. Med. 368, 297-299 (2013)

CañedoAndalia, R.: Para Comprender y Tratar El EscasoEmpleo De Los Recursos De Información Disponibles VíaInfomed Se Necesita Una PerspectivaMultidisciplinar. ACIMED 19 (2009)

CañedoAndalia, R., López Espinosa, J.A.: Infomed: Las AdversidadesDespiertanPotencialidadesDormidas De La Red. ACIMED 19 (2009)

CañedoAndalia, R., Pérez Machín, M., Guzmán Sánchez, M.V., et al.: Aproximaciones a La Visibilidad De La Ciencia y La ProducciónCientífica De Cuba En El Sector De La Salud. ACIMED 21 (2010)

Capote, D.G.: Surgimiento y Evolución De La Política De Ciencia y Tecnología En Cuba (1959-1995) (1996)

CITMA: Resolucion no. 59/2003 (1994)

Cockerill, M.: The Economics of Open Access Publishing. Information Services \& Use 26, 151-157 (2006)

Coiera, E.: Guide to health informatics, 2nd edn. Hodder Arnold, London (2003)

Collier, D., Mahoney, J.: Insights and Pitfalls: Selection Bias in Qualitative Research. World Polit 49, 56-91 (1996)

Committee for Economic Development (CED): Open Standards, Open Source, and Open Innovation: Harnessing the Benefits of Openness (2006)

Dagnino, G.B.: Complex Systems as Key Drivers for the Emergence of a Resource- and Capability-Based Interorganizational Network. E:CO 6, 61-68 (2004)

Davis, K., Schoen, C., Stremikis, K.: Mirror, Mirror on the Wall: How the Performance of the U.S. Health Care System Compares Internationally 2010 Update. Commonwealth Fund (2010)

DíazMartínez, A.G., Abreu García, M.T., Vega Vázquez, H., et al.: Congreso: Nuevo Producto De Plone Para GestionarUnEvento Virtual. ACIMED 21 (2010)

DíazMastellari, M.: Guías De BuenasPrácticasClínicas En CirugíaPediátrica (1999-2006)

Earl, S., Carden, F., Smutylo, T.: Outcome Mapping: Building Learning and Reflection into Development Programs. IDRC (2001)

Ebener, S., Khan, A., Shademani, R., et al.: Knowledge Mapping as a Technique to Support Knowledge Translation. Bulletin of the World Health Organization 84, 636-642 (2006)

Edwards, K.: Epistemic Communities, Situated Learning and Open Source Software Development (2001)

Egbu, C., et.al.: Knowledge Mapping and Bringing about Change for the Sustainable Urban Environment (2006)

Hannan, M.: Ecologies of Organizations: Diversity and Identity. Journal of Economic Perspectives 19, 51-70 (2005)

Infomed: Acercade infomed (2011)

Jardines Méndez, J.B.: Campus Virtual De SaludPública: El ModeloEstratégico. Reunión de Trabajodel Campus Virtual de Salud (2006a)

Jardines Méndez, J.B.: Educación En Red: MuchoMás Que Educación a Distancia: Experiencia De Las UniversidadesMédicasCubanas. EducaciónMédica Superior, 20 (2006b)

Kannampallil, T.G., Schauer, G.F., Cohen, T., et al.: Considering Complexity in Healthcare Systems. J. Biomed. Inform. 44, 943-947 (2011)

Keck, C.W., Reed, G.A.: The Curious Case of Cuba. American Journal of Public Health 102, e13-e20 (2012) 
Lalas Perea, R., Borroto Cruz, R., Hernández Fernández, A.: Universidad Sin Fronteras: Mito o Realidad? RevistaCubana de EducaciónMédica Superior 14, 26-35 (2000)

Lanzara, G.: \&Morner, M.: The Knowledge Ecology of Open-Source Software Projects (2003)

Lavis, J., Lomas, J., Hamid, M., et al.: Assessing Country-Level Efforts to Link Research to Action. Bulletin of the World Health Organization 84, 620-628 (2006)

Maurer, S., Rai, A., Sali, A.: Finding Cures for Tropical Diseases: Is Open Source an Answer. PLoS Medicine 1, 180-183 (2004)

McDonald, P.W., Viehbeck, S.: From Evidence-Based Practice Making to Practice-Based Evidence Making: Creating Communities of (Research) and Practice. Health Promotion Practice 8, 140-144 (2007)

Meneghini, R., Mugnaini, R., Packer, A.: International Versus National Oriented Brazilian Scientific Journals: A Scientometric Analysis Based on SciELO and JCR-ISI Databases. Scientometrics 69, 529-538 (2006)

Meneghini, R., Packer, A.: Is there Science Beyond English? EMBO Reports 8, 112-116 (2007)

Ministerio de SaludPública: TransformacionesNecesarias En El Sistema De SaludPública (2010)

Morrison, K.: Searching for Causality in the Wrong Places. International Journal of Social Research Methodology 15, 15-30 (2012)

Morrison, K.: Educational Philosophy and the Challenge of Complexity Theory. In: Mason, M. (ed.) Complexity Theory and the Philosophy of Education, vol. 2, pp. 16-31. WileyBlackwell, Chichester (2008)

Mueller, M.: Info-Communism? Ownership and Freedom in the Digital Economy. First Monday 13 (2008)

Ofori-Adjei, D., Antes, G., Tharyan, P., et al.: Have Online International Medical Journals made Local Journals Obsolete? PLoS Medicine 3, e359 (2006)

Packer, A.: SciELO as a Model for Scientific Communication in Developing Countries: Origins, Evolution, Current Status, Management and Perspectives of the SciELO Network of Open Access Collections of Ibero-America Journals (2007)

Packer, A.: The Virtual Health Library and the Remodeling of the Health Scientific and Technical Information Flow in Latin America and the Caribbean (2000)

Persaud, D., Nestman, L.: The Utilization of Systematic Outcome Mapping to Improve Performance Management in Health Care. Health Services Management Research 19, 264276 (2006)

PrietoDíaz, V., Quiñones La Rosa, I., RamírezDurán, G., et al.: Impacto De Las Tecnologías De La Información y Las Comunicaciones En La Educación y NuevosParadigmas Del EnfoqueEducativo. EducaciónMédica Superior 25, 95-102 (2011)

Ramírez Machado, S., RizoRodríguez, R., BodeMarín, A.: Plan Capacitante Para Desarrollar La Universidad Virtual De Salud En El Instituto Superior De CienciasMédicas De Santiago De Cuba. MEDISAN 6, 53-59 (2002)

Reimers, K., Johnston, R., Klein, S.: The Difficulty of Studying Inter-Organisational IS Phenomena on Large Scales: Critical Reflections on a Research Journey. Electronic Markets 20, 229-240 (2010)

Reveiz, L., Saenz, C., Murasaki, R.T., et al.: Avances y Retos En El Registro De EnsayosClínicos En América Latina y El Caribe. RevistaPeruana de Medicina Experimental y SaludPública 28, 676-681 (2011)

Robey, D., Boudreau, M.: Accounting for the Contradictory Organizational Consequences of Information Technology: Theoretical Directions and Methodological Implications. Information Systems Research 10, 167-185 (1999)

Rodríguez Pérez, J., Urra González, P.: AtenciónPrimaria En La RedElectrónica De Información De Salud. RevistaCubana de Medicina General Integral 12, 81-86 (1996) 
Rodriguez Pina, R.A., Guerra Avila, E.: MapasConceptuales y Geo-Referencias En Productos y Servicios De InteligenciaEmpresarial. ACIMED 17 (2008)

Ruffini, M.: Using E-Maps to Organize and Navigate Online Content. Educause Quarterly 31, 56-61 (2008)

Scacchi, W., et al.: Towards a Science of Open Source Systems (2010)

Schweik, C., Semenov, A.: The Institutional Design of Open Source Programming: Implications for Addressing Complex Public Policy and Management Problems. First Monday 8 (2003)

Séror, A.: Virtual Health Care Infrastructures: Markets and Hierarchies. In: Proceedings of the 24th International Symposium on Computer-Based Medical Systems, pp. 1-6 (2011)

Séror, A.: Collaboration for Research and Education in Health Care: The Latin American and Caribbean Health Sciences System (BIREME). In: 25th International Symposium on Computer-Based Medical Systems (CBMS), pp. 1-6 (2012)

Séror, A.: Design of Virtual Infrastructures for Public and Private Services: The Indian Health Care System. In: 44th Hawaii International Conference System Sciences (HICSS), pp. 1-9 (2011)

Séror, A.: A Case Analysis of INFOMED: The Cuban National Health Care Telecommunications Network and Portal. Journal of Medical Internet Research 8, e1 (2006a)

Séror, A.: Donor Contributions to National Health Care Systems: The Role of Virtual Infrastructures in Uganda (2006b)

Séror, A.: Internet Infrastructures and Health Care Systems: A Qualitative Comparative Analysis on Networks and Markets in the British National Health Service and Kaiser Permanente. Journal of Medical Internet Research 4 (2002)

Séror, A., FachArteaga, J.: Telecommunications Technology Transfer and the Development of Institutional Infrastructure: The Case of Cuba. Telecommunications Policy 24, 203-221 (2000)

Thrift, N.: Re-Animating the Place of Thought: Transformations of Spatial and Temporal Description. In: The Twenty-First Century. International Workshop on Communities of Practice (2006)

TrinchetSoler, R.M.: El Éxito De Una Red. ACIMED 14 (2006)

Trinchet Soler, R.M., Pedrianes Vigo, M.: Origen, EstadoActual y Perspectivas De La RedNacional De CirugíaPediátrica. ACIMED 12 (2004)

Trist, E.: A Concept of Organizational Ecology. Australian Journal of Management 2, 161-171 (1977)

Urra González, P.: Las Redes De Computadoras Al Servicio De La BibliotecologíaMédica: INFOMED, Una ExperienciaCubana. ACIMED 3, 6-14 (1995)

Vidal Ledo, M.C., Febles Rodríguez, P., Estrada Sentí, C.V.: MapasConceptuales. EducaciónMédica Superior 21 (2007)

Willinsky, J.: The access principle: The case for open access to research and scholarship. Digital Libraries and Electronic Publishing, MIT Press, Boston (2006)

World Health Organization: World Health Statistics (2011)

Yin, R.: Case study research: Design and methods. 4. Sage, London (2009)

Yin, R.: Enhancing the Quality of Case Studies in Health Services Research. Health Services Research 34, 1209-1224 (1999)

Zacca González, G., Diego Olite, F., López Espinosa, J.A.: Universidad Virtual De Salud: Una Nueva Etapa. ACIMED 17 (2008) 